\title{
Standardization prospective in ESONET NoE and a possible implementation on the ANTARES Site
}

\author{
Ingrid Puillat ${ }^{\mathrm{a},{ }^{*}}$, Roland Person ${ }^{\mathrm{a}}$, Claude Leveque ${ }^{\mathrm{b}}$, Jean-François Drogou ${ }^{\mathrm{b}}$, Michael \\ Diepenbroek $^{c}$, Pierre Garreau ${ }^{a}$, Christoph Waldmann ${ }^{c}$ and Yves Auffret ${ }^{a}$
}

\footnotetext{
${ }^{a}$ IFREMER Centre de Brest, Bp 7029280 Plouzané cedex, France

${ }^{\mathrm{b}}$ IFREMER Centre de Toulon, Bp 330, 83507 La Seyne sur mer Cedex, France

c MARUM-Bremen University, Leobener Strasse, Pop 330 440, 28359 Bremen, Germany
}

\author{
*: Corresponding author : Ingrid Puillat, Tel.: +33 2290085 09; fax: +32 29822 46 50, email address \\ : Ingrid.Puillat@ifremer.fr
}

\begin{abstract}
:
ESONET is a Multidisciplinary European Network of Excellence (NoE) associating 50 partners from 14 countries and more than 300 scientists and engineers and dedicated to the lasting integration of research and development in deep sea observatories in Europe. Amongst other actions, it works at establishing seafloor infrastructure that will provide platforms for instrumentation deployed throughout the water column and the geosphere below in a standard manner. Those platforms will provide power for instruments and real-time two-way data communications. This preparatory phase of observatory implementation is intended to select the most suitable standards in order to develop observatories that are interoperable between themselves and which would be able to benefit from the common sharing of facilities. After the ESONET Best Practices Workshop held in Bremen at the end of January 2008, the state of art has been set and some groups working on key standardization topics have been constituted to manage standardization plans. Some outputs are presented hereafter. Those plans will be implemented and tested in the recently-selected four so-called ESONET Demonstration Missions. The ANTARES Site as an ESONET regional node offers some facilities for the next call for demonstration missions. Scientific interest is briefly explained, with a specific focus on needs for oceanography. The technical possibility of new instrument implementation via a secondary junction box is then presented.
\end{abstract}

Keywords: Deep sea observatories; Junction box; Data management; Standardization; Sensor registry; Northern current; Ligurian sea 


\section{General presentation: the ESONET NoE}

ESONET, the European Sea Observatory NETwork is dedicated to federate deep sea observatories around Europe. Indeed several observatory initiatives have already started in Europe with the Geostar class observatories (table 1).

\begin{tabular}{|l|l|}
\hline Observatory name & $\begin{array}{l}\text { Date, EC framework } \\
\text { programme }\end{array}$ \\
\hline Geostar 1 & $1995-1998$ (MAST 3) \\
Geostar 2 & 1999-2001 (MAST 3) \\
ANTARES, & 2002-2004 (FP5) \\
NEMO, NESTOR & \\
ASSEM & $2002-2004$ (FP5) \\
ORION-Geostar-3 & $2002-2005$ (FP5) \\
ESONET CA & $2004-2006$ (FP6) \\
EXOCET/D & $2004-2007$ (FP6) \\
ESONIM & $2004-2007$ (FP6) \\
Nearest & 2006-2009 (FP6) \\
ESONET NoE & Mar. 2007 Feb 2011 \\
EMSO PP & (FP6) \\
& Apr. 2008 Mar; 2012 \\
& (FP7) \\
\hline
\end{tabular}

Table 1: List of main multidisciplinary observatory initiatives in Europe

Observatory initiatives are spreading World-wide since the 1990's. For instance, the Ocean Observatory Initiative (OOI), driven by the USA National Science Foundation (NSF) is developing observatories in 3 steps: coastal observatories, cabled region observatories (the Neptune US observatory) and global observatories. The most advanced network of cabled multidisciplinary observatories is that of Neptune Canada, led by the University of Victoria, whose $800 \mathrm{~km}$ cable was installed by Alcatel Submarine Networks in autumn 2007. The deployment of five nodes and their associated instruments is foreseen for summer 2008. A sixth node will be installed later.

Taiwan decided in 2006 to implement a submarine observatory off the western part of the island (MACHO project). Japan chose to install a twenty-node submarine network, DONET, for seismic monitoring and tsunami alerts (http://www.jamstec.go.jp/jamstec-e/maritec/donet/).

Clearly, the $21^{\text {st }}$ century deep sea observatory is a new technological approach, accepted and being implemented World-wide. Why is this?

Satellite images, even if they provide information over a large time frame (from minutes to years) with a wide range of spatial resolution (from meters to thousands of kilometres) can only cover the upper layer of the sea. Ship survey can only be episodic, and is constrained by weather and (more and more) by ship time cost. Moorings can provide data in real time but not for long periods, usually not for more than a few years, and even then when only configured as a fixed long-term subsurface buoy. The amount of data transmitted by satellite is often too restricted, limiting the sampling frequency and the volume of data that can be 
transmitted in real time, or near real time. Cabled observatories correspond to a complementary solution that is now well recognized: "All countries that can do it should do it and build a World observatory capacity in the seas." (John Delaney); "There is no doubt on the scientific needs of long term." (Antje Boetius), both quotes from the first ESONET All Regions Workshop (Barcelona, Sept. 2007).

The intention of ESONET NoE is not to cable connect regional European observatories between themselves but to network activities in order to build upon existing facilities in the most efficient and cost-effective way, by uniting scientists, engineers, and users of different European nations around a common aim. This is why ESONET is a Network of Excellence according to the definition of the European Commission, which has co-funded the activity for 4 years, starting in March 2007. This network gathers 50 partners (from universities, research centres and industry (including Small and Medium scale Enterprises (SMEs)) in 14 countries; -300 scientists, engineers and technicians.

The scientific questions concern seafloor processes and the water column, as well as marine hydrodynamics, geohazards, climate changes, ecosystem life and evolution. More information can be found on the ESONET website: http://www.esonet-emso.org.

ESONET will not fund observatory infrastructure and implementation directly. It will instead determine how they will be implemented by considering infrastructures, sharing facilities, interoperability and where funding can be found. This is a preparatory phase. After one year of activity a standardization plan was issued, and the corresponding technologies are now in development or under adaptation. This is the focus of this article, and we will present the ANTARES Site as an ESONET node for testing and sharing facilities, together with its scientific interests.

\section{Standardization in ESONET}

A major objective of ESONET is to facilitate the transition from conventional, stand-alone mono-disciplinary instrumented ocean observations into a complex network of observatories with commonly usable data services. The heterogeneity of organizational and technical approaches, equipment and methods used in the observing stations, as well as the dynamics of scientific and technical developments, requires common agreements, adoption and/or development of common standards and tools, and adaptation to the needs of users. This will ensure that the shared observations and data products are accessible, comparable, and comprehensive. In January 2008 the first ESONET Best Practices Workshop was held in Bremen, led by our partner KDM/ University of Bremen (MARUM team). The workshop was structured into five sessions that covered interfacing, underwater intervention, data management, scientific demands and existing infrastructure issues. The idea is to make efficient use of existing knowledge and develop concepts that are sustainable within future observatory infrastructures. In the following sections we focus on interfacing and data management only. A complete report can be requested from the ESONET coordination team. 


\subsection{ESONET Sensor registry}

The sensor registry concept (Fig. 1) as conceived within the ESONET project will form the nucleus around which the basic functional blocks of an interoperable observatory system will be grouped. In its simplest form it will consist of a web interface that allows a user of an observatory to insert all necessary metadata to describe its function. It is necessary that the registry will act as a dynamic registry for identifying the current status and whereabouts of a given sensor. It will be implemented to define and include descriptive metadata to the data stream coming from the individual sensor system.

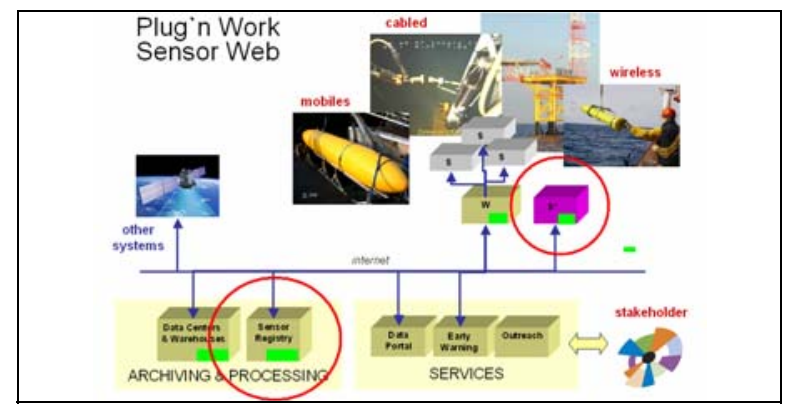

(a):

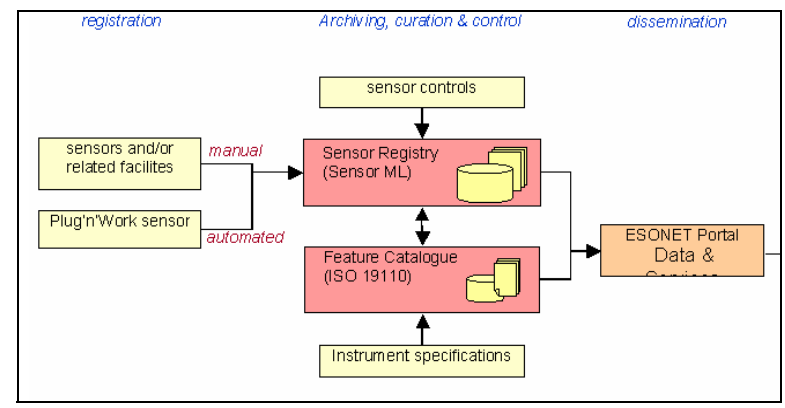

(b)

Figure 1: Concept of ESONET Sensor registry as part of the Plug and work sensor web (a) and its functionalities (b)

The technical implementation will be carried out on different levels starting at the sensor interface level and ending at the data networking level. On the hardware level different approaches are possible which centre on the proposed IEEE 1451 standard. This has led to a specific concept for sensor networks by the Open Geospatial Consortium (OGC) Sensor Web Enablement (SWE) team [1]. Essential building blocks are OGC Web-Services, SensorML [2], Sensor Observation Service, Sensor Planning Service, Observations \& Measurement (O\&M) and TransducerML (which like SensorML can embed IEEE 1451) [3]. To further improve the SWE concept, the OGC has initiated a test bed (OWS-3) in 2005. This concept enables the technical and semantic interoperability between system components and between different 
monitoring and archiving systems. An essential first step is a sensor registry which will supply a dynamic inventory of equipment in use and sensor platforms. This registry will be available as a service component to ESONET and the wider community.

\subsection{Plug'n work instruments}

An important issue in regard to the technical implementation of ocean observatories is to have a clear definition of the interfaces between the basic building blocks. This is an indispensable step in the design of an interoperable system on the device level. Within ESONET it is planned to make use of the IEEE 1451 standard which allows for the envisioned plug and work functionality.

As most sensors used in ocean sciences do not communicate any metadata describing the instrument characteristics in a standard way, the PUCK (Programmable Underwater Connector with Knowledge) technology, for instance, can help to automate the configuration process by physically storing information about the instrument within the instrument itself. The information may include metadata descriptions, driver software, GUI software, or any other information deemed relevant by the observing system. The host platform can retrieve the information from the PUCK using a simple protocol, and deal with the information appropriately. For example, the system may install and execute drivers that have been retrieved from the PUCK. This automated configuration process is known as "plug-and-work". For more information, see the Marine Plug-and-Work Consortium website http://www.mbari.org/pw. Another possibility is the implementation of a Smart Sensor Interface that provides network infrastructure services at different levels

- an electronic biofouling interface;

- time reference;

compatible with a cable network, tethered buoy or autonomous observatories. With Serial and Ethernet instrument interfaces, it works as a plug-and-play interface.

This interface can be implemented in different locations: as a bridge between the IP network and the instrument, or it can be integrated inside a network infrastructure (junction box...) or inside a new instrument. This technology is under development at the Europole Mer in Brest, gathering Bretagne University, IFREMER and ENSIETA Engineering School for this project. Negotiations are ongoing to involve MBARI, NEPTUNE Canada and European partners in the project.

\subsection{Data management in ESONET}

The data and information management plan is led by our partner KDM/Bremen University. A first version is edited as a generic and dynamic document meeting today's requirements. In its chosen form as a wiki-based structure the plan is open for the incorporation of further development in the context of data capture, data flow, and data migration and will be available at any time in its respectively updated form at http://wiki.pangaea.de/wiki/Data_and_information_management_plan.

With increasing integration of observatories over time, in particular through the demonstration cases, specifications can be added and the document can be adapted to the evolutionary design of the ESONET observatories network. The fundamental underlying 
principle for this plan is the full and open exchange of data and information for scientific and educational purposes (GEOSS - "Global Earth Observation System of Systems" data sharing principles). After the Best Practices workshop, the plan has been detailed as shown in figure 2. Structuring groups are working on the different steps of the plan from the data capture to the data retrieving and viewing with data quality control. Available standards are being listed to assess their suitability for ESONET observatories. Other European initiatives like EuroSITES, a FP7 observatory project more specific to the water column monitoring, and SeaDataNet, a FP6 project dedicated to sea data management in Europe, are collaborating with the ESONET data management team; some common actions will be initiated.

A complement to the data management system and part of the data and information management plan is the creation on an interactive topology of existing regional observatories, which itself brings the complete state of the knowledge on the sites and which will eventually be shared among regional observatories through a common data infrastructure based on global standards. This mapping will help the development of strategies for necessary adaptations and extensions of existing nodes. A user friendly Asynchronous JavaScript and XML (AJAX) web interface allows highly flexible configurations of topology models (e.g. ISO 19110 (feature catalogue) compliant and/or according to SensorML), as well as data entry for example of the network nodes. The ESONET interactive topology is publicly available via the internet at http://features.pangaea.de/map.php.

This topology offers the interested public the opportunity to explore the so-visualized project with an active Google ${ }^{\mathrm{TM}}$ Earth based map that serves further and more detailed information on selected items.

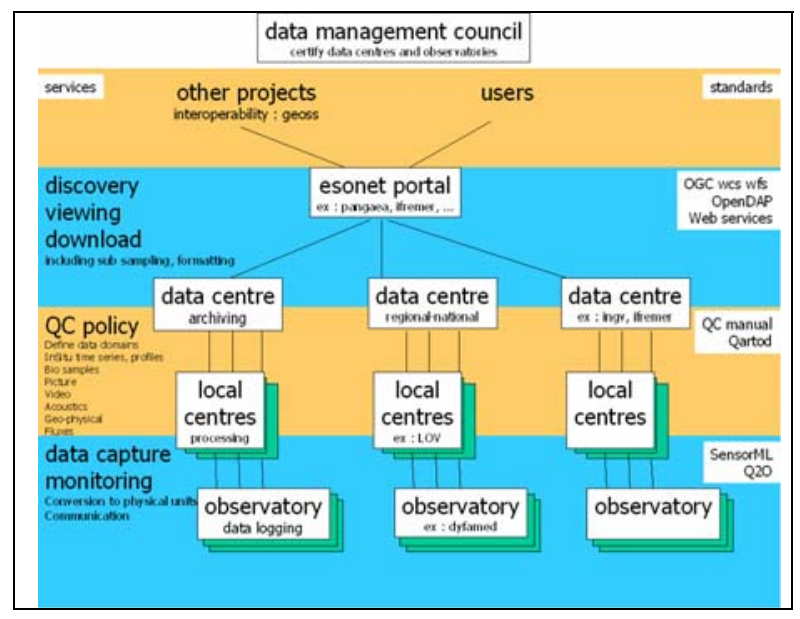

Fig 2: schematic representation of the ESONET data management plan. The ESONET sensor registry is not represented here for simplification purposes. 


\section{The ANTARES site as a regional node in ESONET.}

\subsection{Scientific needs}

The ANTARES site is located in the north-western Mediterranean Sea at the boundary between the Ligurian Sea and the Gulf of Lyon, South of the Porquerolles Island (France, Var). Scientific studies in this zone, sandwiched between two already well studied areas, are less detailed and so far not well enough documented. Consequently, most of the conclusions are deduced from the adjoining western and eastern experiments and observations.

The scientific interest of the zone is multidisciplinary. Indeed, the proximity of canyons raises the opportunity for geophysical studies, for instance of gravity flows. In the proper ANTARES zone, even if it is expected to be a "quiet, secure zone", no specific studies have so far been made. The area also has a great interest for seismology studies, and some seismometers are already installed. The ANTARES site is also well located for marine mammal monitoring as more than twenty species can be found in the Ligurian sea. As it would be too long and not suitable to detail here the different scientific needs for each discipline, only a focus on oceanography is given hereafter.

Along the northern continental slope of the Liguro-Provencal basin, the modified Atlantic Water flows as the so called Northern Current (NC) on a cyclonic circulation (satellite image in Fig. 3) as documented in numerous articles (e.g.[4-8]). It is also named the Ligurian current, the Liguro-Provencal current or the Catalan current.

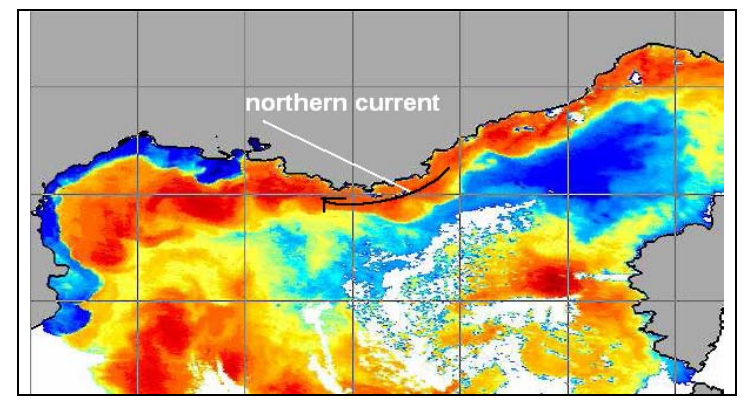

Fig. 3: Sea Surface Temperature (SST) image of the Liguro-Provencal basin (Eastern French Mediterranean zone to Corsica), December 9, 2003

The current features are well known: with a mean speed of $25-35 \mathrm{~cm} \cdot \mathrm{s}^{-1}, \sim 25 \mathrm{~km}$ wide and about 300-400 $\mathrm{m}$ deep, it presents an important seasonal variation. Its flux is maximum in winter (December to May: 1.5-2 Sv ${ }^{1}$ down to $700 \mathrm{dbar}^{2}$, [9]). Variation of its structure is also observed: it is wider and shallower in summer with reduced mesoscale activities. In winter the $\mathrm{NC}$ becomes thicker, narrower and tends to flow closer to the slope. Consequently, the current core position can vary from $-20 \mathrm{~km}$ to $+35 \mathrm{~km}$ from a mean position, off Marseille for example [10]. In the ANTARES location the node can be out of the current or in the current as

\footnotetext{
${ }^{1}$ Ocean currents are measured in Sverdrup (Sv): $1 \mathrm{~Sv}$ is equivalent to a volume flow of $10^{6} \mathrm{~m}^{3} . \mathrm{s}^{-1}$

${ }^{2}$ Equivalent to a depth of 700 metres
} 
depicted by the numerical results from the MARS model [11] (Fig. 4), inducing variations of the local current speed and direction.
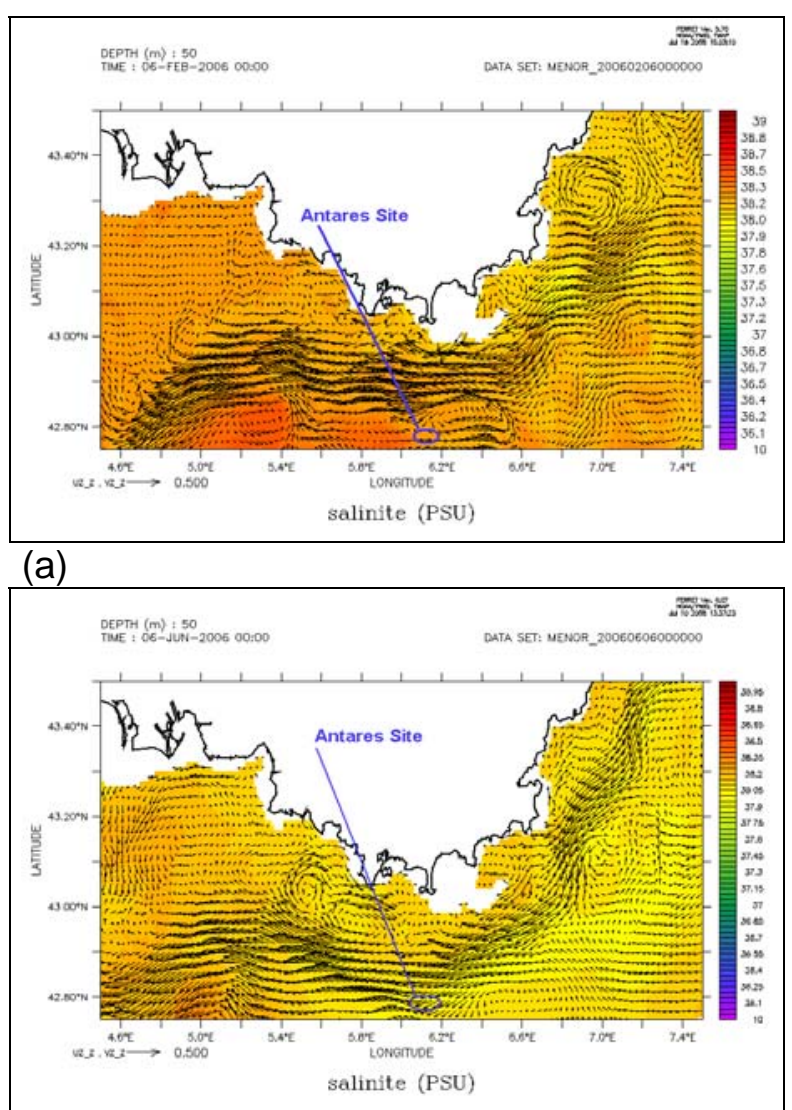

(b)

Fig. 4: Results from MARS model: current field at 50m; June 2, 2006 (a) and June 6, 2006 (b)

Bethoux et al. [12] explained this variability by the permanent contribution of the Western Corsica Current $(0.7 \mathrm{~Sv})$ and the seasonal contribution of the flow coming from the Tyrrhenian Sea through the Corsica Channel, known also as the Eastern Corsica Current (from $2 \mathrm{~Sv}$ in late autumn to a minimum of $0.2 \mathrm{~Sv}$ in summer). The dense water formation in the central zone of the Ligurian sea and the Gulf of Lyon - a consequence of meteorological forcing in winter - is also expected to enhance the NC flow by geostrophic adjustment [13]. Out of the Winter period the NC could be forced by the freshwater discharge along the coast after heavy rains in autumn [6]. 


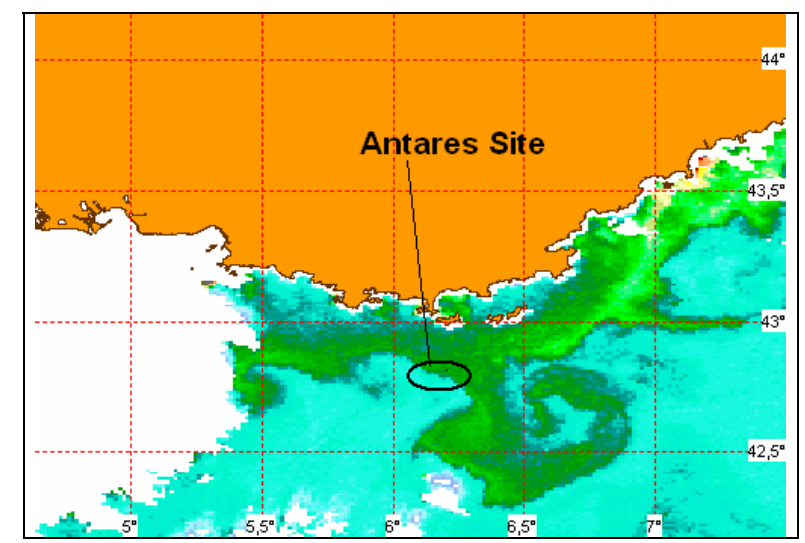

Fig. 5: Example of a mesoscale filament occurring at the ANTARES site; observed on a turbidity satellite image, March 9, 2006

During wintertime, the baroclinically instable NC develops a strong mesoscale activity characterised by meanders with both amplitudes and wavelengths from a few tens up to one hundred kilometres [14]. With a phase speed of 10-20 km.day ${ }^{-1}$ they induce an extremely large variability. Spiralling filaments (cyclonic eddy) and eddy-like structures similar to that observed on the turbidity image in figure 5 are typical patterns, inducing significant southward currents on the ANTARES site in the Atlantic Water layer at least, instead of "usual" westward and south-westward current.

As observed on infrared satellite images, a thermal (and density) front is associated with the current, setting the offshore boundary of the current. Frontogenic processes and mesoscale activity of the current are expected to be associated to vertical velocities, as is generally the case for baroclinically unstable frontal jet systems[15]. Several theories are possible: for example the upwelling of lighter water in the current and downwelling near the front [15], or divergence (and upwelling) near the offshore limit of the current and convergence (downwelling) inside the frontal zone [16]. Vertical velocity changes have been more generally deduced from patterns in phytoplankton biomass, salinity, and temperature [17]. Physical data are missing to derive vertical velocities and theoretical distributions of vertical velocities have been used as hypotheses to explain biogeochemical observations [18]. Consequently, there is a real need for physical oceanography monitoring dedicated to mesoscale activity. Relatively high resolution monitoring would help in the understanding of vertical velocity generating processes associated to mesoscale structures, and over the long term, the influence of the seasonal and inter-annual signal (hard winter condition influence) would be understood. A special focus is needed on the deepest layer where significant horizontal currents have been recently observed [19]. In addition, inputs of cool and dense water formed on the shelf in winter and going down across the slope to the bottom are expected. More generally, exchanges between coastal zone and open sea across the NC are far from being well understood and quantified. For instance some subsurface $(50 \mathrm{~m})$ buoys launched in the NC have been observed to directly go into the open sea, leaving the NC, but no explanation has yet been given [20]. High resolution and long term observation in the NC area is also needed to better understand biogeochemical processes. 


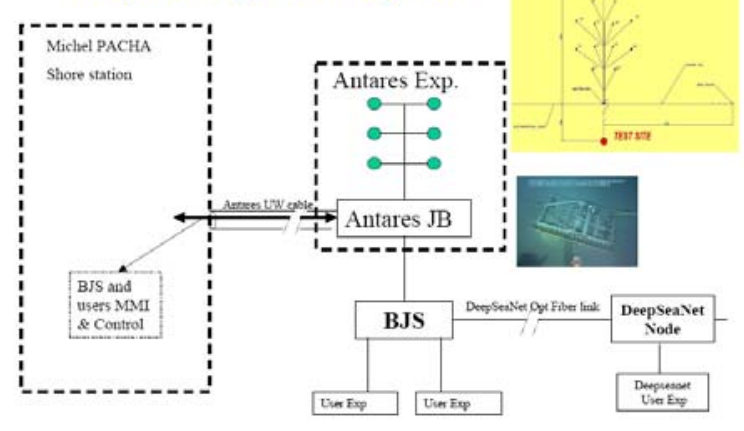

\subsection{Technical opportunity: The ANTARES secondary junction box: a deep sea test bed for instrumentation developments.}

IFREMER, in partnership with Centre de Physique des Particules de Marseille, Geosciences Azur and INSU, also with the financial support from the Provence Alpes Cote d'Azur (PACA) French region, is proposing to benefit from the ANTARES Site infrastructure to install a Secondary Junction Box (SJB) to provide additional connections for deep sea experimentation. The idea is to study and plug a ANTARES SJB to the main junction box already at the ANTARES neutrino telescope in order to accomodate new scientific, technological and industry experiments (Fig. 6).

Connection standards for power supply and communications on the satellite instrument network will be selected, where possible, using World-wide interoperability standards. Indeed, at least four 300/400VDC (up to $1 \mathrm{~kW}$ ) and a $100 \mathrm{Mb}$ Ethernet user port will be available. The future MOGLI (MObile GLass fibre Information system) network, a demonstrator dedicated to geophysics risk monitoring (seismic, tsunami and gravity flow) based on DeepSeaNet technology developed by IFREMER for long distance data recovery and instrument control, will be connected to the SJB for test.

The SJB will be installed far enough from the telescope to avoid any perturbation due to experiments. A specific structure dedicated to site access is being developed: candidate applications will be processed, gathered and assessed by the CPPM Infrastructure Access Unit (Service d'Accès à l'Infrastructure, SIA) and validated by the Acces Technical Committee of CPPM (Commission Technique d'Accès, CTA), constituted of members selected by ANTARES and IFREMER. Deployment is foreseen for the second half of 2009, with first operations to follow.

Fig. 6: Concept of the Secondary Junction Box at the ANTARES site

\section{Conclusion : Possibility of a demonstration mission on ANTARES}

After one year of ESONET activity, some technical solutions and methodologies have been selected and need to be proven. For this reason some demonstration missions working as ESONET internal calls are organised. For the first call four proposals have been accepted: MARAMARA (Marmara node), LOOME (Åkon Mosby node), MOMAR-D (Azores node), LIDO (twin: Gulf of Cadiz and Sicily nodes). The next call should be opened in September 2008. The ANTARES site presents all the capabilities for such a demonstration mission with real time data acquisition. Indeed the already existing infrastructure plus the upcoming secondary junction box will allow the extension of the present network. In addition, in order to test the newly developing instruments and observatory technologies, some testing facilities need to be available for developers, with compatiblity at a European level. A specific action is undertaken for this purpose. Indeed an address book of core group participants is prepared with available infrastructures listed for: 
- land bases, infrastructures and equipment with environmental test facilities and sensor and system calibration facilities;

- coastal sea test infrastructures;

- deep water test infrastructures.

A guide with procedures for environmental tests, sensor and system calibrations is under preparation and could be applied at the ANTARES site.

\section{Acknowledgments}

Since the ESONET activity is a collaborative effort involving partners working in many different are, our acknowledgment is firstly dedicated to all participating partners. This work is undertaken in the framework of the FP6 European Commission program under the contract GOCE-036851. We also acknowledge the support of the European Commission .

\section{References}

[1] M. Botts \& M. Riechardt, Sensor web Enablement White Paper. 2005.

[2] M. Botts, Sensor Model Language (SensorML) for in-situ and Remote Sensors RP, Version 1.0 .0 beta. 2004.

[3] S. Havens \& J. Ricker. Transducer Markup Language Data Streaming Specification. 2005.

[4] C. Albérola, C. Millot \& J. Font.

On the seasonal and mesoscale variabilities of the Northern Current during the PRIMO-0 experiment in the western Mediterranean Sea. Oceanologica Acta 1995;18:163-92.

[5] J-P. Béthoux \& L. Prieur

Hydrologie et circulation en Méditerranée Nord-Occidentale. Pétrole et Techniques 1983;299:25-34.

[6] J-P. Béthoux, L. Prieur, \& J. Bong. Le courant Ligure au large de Nice. Océanographie pélagique Méditerranéenne, H.J.M.A.P. Nival Editor 1988:59-67.

[7] C. Sammari, C. Millot \& L. Prieur, Aspects of the seasonal and mesoscale variabilities of the Northern Current in the western Mediterranean Sea inferred from the PROLIG-2 and PROS-6 experiments. Deep Sea Research Part I: Oceanographic Research Papers 1995;42:893-917.

[8] I. Taupier-Letage \& C. Millot, General hydrodynamical features in the Ligurian Sea inferred from the DYOME experiment. Oceanologica Acta 1986;2:119-31.

[9] C. Millot, Circulation in the Western Mediterranean Sea. Journal of Marine Systems 1999;20:423-42.

[10] P. Conan P \& C. Millot Variability of the Northern Current in the Western Mediterranean Sea from February to June 1992. Oceanologica Acta 1995;18:193-205.

[11] G. André, P. Garreau, V. Garnier \& P. Fraunié Modelled variability of the Sea surface circulation in the north werstern Meditérranean Sea and in the Gulf of Lions. Ocean Dynamics 2005;55:294-303. 
[12] J-P. Béthoux, L. Prieur \& F. Nyffeler,

The water circulation in the North Western Mediterranean Sea, its relation with wind and atmospheric pressure,. Hydrodynamics of semi enclosed seas 1982:129-42.

[13] M. Crépon\& M. Boukthir

Effect of deep water formation on the circulation of the Ligurian Basin. Annales Geophysicae 1987;5B:43-8.

[14] M. Crépon. L. Wald \&J-M. Monget,

Low frequency waves in the Ligurian sea during December 1977. ournal of Geophysical Research 1982;87:595-600.

[15] J.T. Allen, L. Brown, R. Sanders, C. Mark Moore, A. Mustard, S. Fielding et al.

Diatom carbon export enhanced by silicate upwelling in the northeast Atlantic. Nature 2005;437:728-32.

[16] J. Boucher , F. Ibanez \& L. Prieur

Daily and seasonal variations in the spatial distribution of zooplankton populations in relation to the physical structure in the Ligurian front. Journal of Marine Reseach $1987 ; 45: 133-73$.

[17] B. Zakardjian B \& L.Prieur

Biological and chemical signs of upward motions in permanent geostrophic fronts of the Western Mediterranean. Journal of Geophysical Research-Oceans 1998;103:27849-66.

[18] L. Stemmann, L. Prieur, L. Legendre, I. Taupier-Letage, M. Picheral, L. Guidi, et al.

Effects of frontal processes on marine aggregate dynamics and fluxes: An interannual study in a permanent geostrophic. Journal of Marine Systems 2008;70:1-20.

[19] I. Taupier-Letage, personal communication

[20] P. Garreau, IFREMER, unpublished data 